\title{
PRAÇA DA PROSA: UM ANTEPROJETO URBANO PARA A CIDADE DE SANTA HELENA-PB
}

\author{
PROSA SQUARE: AN URBAN PROJECT FOR THE CITY OF SANTA \\ HELENA-PB
}

\author{
Ana Victoria Pinheiro Dias ${ }^{1}$ \\ Mirela Davi de Melo $^{2}$ \\ Camilla Furtado de Figueiredo ${ }^{3}$ \\ Pollyanna Priscila de Souza Lima ${ }^{4}$ \\ Joálisson Dias Cunha ${ }^{5}$ \\ Isabel Sobral de Abreu e Lima ${ }^{6}$
}

RESUMO: Objetivo: Analisar o recorte escolhido, a fim de propor um anteprojeto para uma praça na cidade de Santa Helena-PB. Método: O estudo foi desenvolvido a partir da proposta metodológica fundamentada no Manual de Diretrizes de abordagem contemporânea, com a sucessão de diversas etapas que permitirão a leitura do espaço urbano, mapeamento dos problemas e potencialidades, identificação de prioridades e alternativas, análise do entorno e do terreno, entre outras. O estudo foi desenvolvido por meio de uma pesquisa aplicada, descritiva, observacional e exploratória, a ser realizado na cidade de Santa Helena. Resultados e discussões: Com relação aos resultados, através do estudo foi possível conhecer as principais necessidades da área e as possibilidades, através de um mapeamento que também permitiu identificar eventuais problemas e as prioridades a serem supridas por meio da aplicação de um projeto. Inicialmente, foi constatada a viabilidade da proposta, que traz o potencial de incentivar diversas modalidades de equipamentos e formas de uso, por meio do lazer, participação e interação social, proporcionando resultados positivos para a população local. Considerações finais: Conclui-se que a criação de ambientes capazes de oferecer significado e conforto à comunidade é essencial para atender às demandas sociais na ocupação de espaços urbanos em desuso e, nesse contexto, o anteprojeto proposto para a criação da praça no contexto analisado, contribui para a satisfação e o sentimento de pertencimento ao lugar, mostrando a importância de qualificar o

\footnotetext{
${ }^{1}$ Graduada em Arquitetura e Urbanismo pela Faculdade Santa Maria, Cajazeiras, Paraíba.

2 Docente da Faculdade Santa Maria, Cajazeiras, Paraíba.

${ }^{3}$ Docente da Faculdade Santa Maria, Cajazeiras, Paraíba.

4 Docente da Faculdade Santa Maria, Cajazeiras, Paraíba.

5 Docente da Faculdade Santa Maria, Cajazeiras, Paraíba.

${ }^{6}$ Docente da Faculdade Santa Maria, Cajazeiras, Paraíba.
} 
espaço público para promover a aceitação dos equipamentos pelas pessoas e, não apenas, tratar a ocupação dessas áreas de maneira secundária e imediatista.

Descritores: Cidade. Projeto. Público. Urbano.

ABSTRACT: Objective: To analyze the chosen clipping in order to propose a draft for a square in the city of Santa Helena - PB. Method: The study was developed from the methodological proposal based on the Manual of Guidelines of contemporary approach, with the succession of several steps that will allow the reading of urban space, mapping of problems and potentialities, identification of priorities and alternatives, analysis of the surroundings and of the land, among others. The study was developed through an applied, descriptive, observational and exploratory research, to be conducted in the city of Santa Helena. Results and discussions: With regard to the results, the study allowed knowing the main needs of the area and the possibilities, through a mapping that also allowed identifying problems and priorities to be met through the application of a project. Initially, there was the analysis of the viability of the proposal, which brings the potential to encourage various types of equipment and use through leisure, participation and social interaction, providing positive results for the local population. Final thoughts: The creation of environments capable of offering meaning and comfort to the community is essential to meet the social demands in the occupation of disused urban spaces and, in this context, the proposed preliminary project for the creation of the square in the analyzed context contributes to the satisfaction and sense of belonging to the place, showing the importance of qualifying the public space to promote the acceptance of equipment by people and not only treat the occupation of these areas in a secondary and immediate way.

Descriptors: City. Public. Project. Urban. 


\section{INTRODUÇÃO}

O espaço público desempenha uma importante função nas relações entre a vida social e a organização espacial, ocupando papel decisivo para o exercício da cidadania, as trocas de experiências e os encontros, a prática do lazer e de atividades econômicas, entre outras manifestações. $O$ espaço público também atua evidenciando diferenças entre as pessoas e os grupos sociais, mostrando-se lugar de apropriação e usos diversos (CABRAL; ROSSETTO; SABOYA, 2016).

Estudar o tema é uma forma de compreender a função do arquiteto e urbanista ao interferir no espaço urbano, criando locais que podem refletir positivamente sobre a qualidade de vida das pessoas, vencendo as barreiras da exclusão social e garantindo a acessibilidade desses espaços enquanto bens sociais que devem estar disponíveis a todos. Dessa forma, o ponto de partida é a análise e o diagnóstico dos espaços quanto às necessidades do perímetro em estudo e os impactos que podem ser gerados para a comunidade.

Entende-se que a cidade contemporânea é de uma complexidade crescente, na qual as relações sociais são produzidas a partir da organização do espaço que, muitas vezes, não é adequado às necessidades das pessoas. Ao mesmo tempo, muitos espaços públicos urbanos têm servido à acumulação, tendo suas formas de uso readaptadas para atender à dinâmica capitalista. Contudo, as cidades surgiram como forma de suprir às necessidades humanas da convivência em grupo. A cidade cresce e se transforma, gerando novas áreas de ocupação e evidenciando vazios urbanos que podem ser reestruturados para melhorar a qualidade dos espaços (VELLOSO, 2015).

O espaço público deve ser visto como facilitador da urbanidade, ou seja, dos encontros entre as pessoas, da interação e convivência em um mesmo espaço, acompanhando o desempenho de funções do cotidiano. O espaço deve ser criado para ser vivido, representando um lugar de liberdade, integrado às necessidades da 
comunidade e servindo às mais diversas formas de uso que ressaltem o valor do mesmo como bem social (MONTEIRO, 2015).

No intuito de criar espaços públicos relevantes para a população nas cidades, projetos devem ser propostos a partir de um conjunto de etapas previamente planejadas, elaboradas e empreendidas. Baseando-se em um diagnóstico de necessidades, mapeamento das condições gerais da área, identificação de impactos, entre outros requisitos essenciais para garantir a acessibilidade, uso e apropriação dos espaços a serem implementados.

A partir de todas essas considerações acerca do espaço público, da relevância para o cotidiano nas cidades e para a qualidade de vida das pessoas, o presente trabalho foi desenvolvido para responder ao seguinte problema de pesquisa: como utilizar espaços públicos em desuso para que estes possam ser incluídos nos espaços de lazer de uma cidade?

A relevância do presente estudo se destaca pela contribuição que busca trazer ao conhecimento acadêmico, além de difundir novas informações sobre a importância de aproveitar espaços públicos para melhorar a qualidade de vida nas cidades. $\mathrm{O}$ estudo tem como objetivo elaborar um anteprojeto de uma praça para a cidade de Santa Helena-PB.

\section{MÉTODO}

O presente estudo é definido como pesquisa aplicada, que busca gerar conhecimentos passíveis de aplicação prática e voltados a solucionar problemas específicos. É definido, ainda, como estudo descritivo, observacional e de cunho exploratório.

Será realizada, ainda, uma pesquisa bibliográfica, a qual é utilizada para fundamentar teoricamente o objetivo de estudo, auxiliando com elementos que norteiam análise futura de dados obtidos. Esse tipo de pesquisa vai além da simples observação de dados nas fontes pesquisadas, imprimindo sobre eles a teoria, compreensão crítica acerca do significado neles existente (LIMA; MIOTO, 2007). 
A análise das informações obtidas a partir da pesquisa bibliográfica, das observações e resultados alcançados, será realizada de maneira descritiva e crítica, confrontando ideias e fatos através de diferentes opiniões, ou seja, argumentos e contra-argumentos, vinculando fatos ao seu contexto social e mostrando-se como método de investigação da realidade por meio de contradições inerentes aos fenômenos.

O estudo foi realizado na cidade de Santa Helena, figura 1, localizada na Região de Cajazeiras, Estado da Paraíba. De acordo com dados do Instituto Brasileiro de Geografia e Estatística, a população do município em 2010 era de 5.369 habitantes. As estimativas para 2018 apontam população de 5.907 pessoas (IBGE, 2018).

\section{RESULTADOS E DISCUSSÕES}

Com base no processo metodológico que proporciona a leitura visual do espaço urbano, proposta por Gatti (2017), que trata "O espaço público de uma cidade é o lugar do lazer, do descanso, da conversa corriqueira, da livre circulação, da troca e, sobretudo, da possibilidade do encontro com o outro", pode-se alcançar resultados que viabilizem uma intervenção positiva na área estudada, e que passam a ser descritos.

Com este posicionamento, o andamento da análise foi realizado inicialmente a partir do Mapeamento dos Pontos de Interesse, que proporciona um contato inicial com uma leitura mais ampla do espaço, fornecendo dados importantes referentes ao abastecimento de determinados recursos na área que, segundo Gatti (2017), compreende áreas verdes, equipamentos públicos, comércio e serviços, e o quanto cada porção do território demanda ou não o investimento em novos espaços públicos ou na requalificação dos espaços existentes. 


\section{Leitura do espaço urbano}

A partir dos fatores que são categorizados no Mapeamento dos Pontos de Interesse, foi possível concluir, a partir da elaboração do mapa, que a área é extremamente carente de espaços verdes, tendo em vista que este processo metodológico entende como áreas verdes, as praças e parques, sendo que a áreas verdes demarcadas no recorte se apresenta de forma pontual em apenas dois pontos como pode-se observar no mapeamento, desta forma a introdução de áreas verdes se caracteriza como potencial interesse na logística de desenvolvimento projetual.

O mapeamento consecutivamente permite a leitura de equipamentos significativos, sendo entes representados pela educação pois o perímetro abriga três escolas, como também o considerável número de estabelecimentos comerciais. $\mathrm{O}$ recorte também engloba o campo de futebol da cidade, sendo este demarcado como área esportiva. Diante desta dinâmica de demarcação de pontos de interesse, tornase notório a diversidade de atividades desenvolvidas no perímetro do recorte compreendido no campo de estudo do presente trabalho, como também estabelece uma identidade dos perfis de usuários em potencial que pode desfrutar do projeto. A partir dessa análise preliminar, já foi possível entender necessidades a serem supridas.

Consecutivamente, foi realizado o Mapeamento dos Problemas e Potencialidades, ressaltando que, segundo Gatti (2017), a realização do mesmo permite visualizar as relações entre os usos existentes da cidade e a qualidade do espaço urbano. Trata-se de uma relação que permite identificar novas potencialidades de projetos. Dessa forma, o mapeamento demonstra, de maneira clara, que a área do recorte apresenta carências de equipamentos de cultura, lazer e esporte, como também, confirma novamente a carência de áreas verdades.

É possível visualizar, ainda, o conflito na movimentação de carros e pedestres. Este mapeamento ainda permite a visualização da denominada área de 
estar ao ar livre, que a metodologia entende como apropriação de cidadão para com o espaço público mesmo este não oferecendo qualquer tipo de infraestrutura. Entende-se que este é simplesmente um ato inconsciente do ser humano perante as necessidades, que lhes permite usufruir do que está ao seu dispor. Esses dados foram observados a partir da leitura do espaço, de maneira contextualizada às necessidades, fornecendo um filtro para a elaboração projetual.

Outro pressuposto é o de analisar os espaços públicos existentes, tendo em mente as praças, parques e ruas, etapa que foi desenvolvida no intuito de enfatizar os mapas já mencionados anteriormente, pois apresentam de maneira clara, a ausência de praças e parques, descartando assim a ideia da requalificação e direcionando a pesquisa para entender de maneira mais detalhada as necessidades que a área apresenta. Nesta etapa da análise, fica evidente como o estudo preliminar visual de leitura do espaço e das atividades neste desenvolvidas, são o que proporcionam a efetividade do uso, pois o projeto atende exatamente à demanda da área em estudo.

A partir desta estruturação de entender como se encontra o espaço público para intervenção, pode-se estabelecer o anteprojeto de uma praça como potencial para suprir as informações filtradas pela análise dos mapas, sendo estas necessidades, entre outras, a demanda de áreas verdes, suprida pela arborização com plantas nativas da caatinga, como também por vegetações que se adaptem ao clima, além de recursos de acessibilidade para todos os tipos de usuário, pois o projeto se torna bastante abrangente por incluir um perímetro de grande volume residencial, de núcleos educacionais, estabelecimentos comerciais e área destinada à prática de esportes. Por fim, a segurança e atividades de permanência.

A etapa seguinte foi a identificação das prioridades da área que, segundo Gatti (2017), evidencia o cenário que integra as condições locais, identificando prioridades para a aplicação de investimentos, seja para a criação de novos espaços públicos ou para a melhoria dos espaços existentes.

É justamente deparando-se nesta fase que a elaboração de um novo projeto para o recorte torna-se mais pertinente, frente à realidade do perímetro, tendo em vista que o investimento se torna um bem maior para a sociedade e, para isso, é preciso guardar uma certa coerência com a realidade da comunidade. Ao identificar 
as prioridades, o projeto busca enfatizar os pontos essenciais para democratizar o acesso e usufruto do espaço público.

O manual ainda apresenta mais uma etapa que integra a leitura do espaço urbano, que se refere à identificação de alternativas, na qual são apresentadas as soluções alternativas para o modo de vida contemporâneo, como por exemplo realizar o fechamento de ruas, durante determinados dias da semana, para incentivar o convívio e a utilização dos espaços públicos, com suas diversificadas formas de uso. Alternativas como estas são soluções peculiares diante de cada projeto, onde é possível trazer demandas para a realidade do anteprojeto da praça, o que não se aplica de maneira eficaz na presente proposta de intervenção, pois o recorte escolhido para a implantação do projeto não apresenta quaisquer condições de manejo alternativo, uma vez que é caracterizada também como vazio urbano sem qualquer infraestrutura presente.

\section{Projetos correlatos}

Foram considerados projetos correlatos do mesmo segmento temático como forma de embasar o desenvolvimento projetual do presente trabalho, que tem por finalidade propor um anteprojeto de uma praça. O primeiro correlato trata-se do projeto nomeado "Na Natureza Selvagem", o segundo refere-se ao premiado em $1^{\circ}$ Lugar - Concurso de projetos: "Praça Colinas de Anhanguera / HUS", onde ambos apresentam singularidades projetuais importantes de serem vislumbradas como um formato de gerenciar a dinâmica deste tipo de projeto que trabalha com espaço público de forma tão acolhedora e acessível às distintas formas de uso.

Entre os aspectos marcantes do projeto, podem-se enfatizar, entre outros, as características do local de implantação, sendo este cercado por áreas residenciais, como também uma escola que se localiza diante da mesma, já demarcando de certo modo o tipo de usuário que se apropriará do espaço com mais frequência.

O projeto delimita zonas de interesse para os diferentes tipos de usuários, de modo que a marcação destas áreas ocorre de forma natural por estruturas que 
modelam o espaço de forma harmoniosa, como a própria utilização do piso como meio para definir estes usos e modelar a praça.

De acordo com os critérios de demarcação de usos, que a área se estabelece como ponto de referência dentro do perímetro que foi inserida, como também marca no projeto, zonas para jogos e brincadeiras, mesclando o uso e a variedade do público que utilizará o espaço.

A proposta apresenta o uso de diferentes materiais, onde isso é exposto na parte projetual responsável por objetos do parquinho que se integram com o ambiente natural criando desta forma um jogo de dinâmicas singulares que não se apropria do espaço, mas que se integra ao mesmo sobre um padrão de harmonia.

No projeto, a vegetação foi escolhida com a intenção de introduzir um cenário de integração entre a vegetação existente e a implantada, pensando nesta arborização de forma mais abrangente, como o comportamento ao longo do ano e que tipo de seções podem trazer ao projeto e consecutivamente aos seus usuários.

Por fim, a proposta o projeto $\mathrm{Na}$ Natureza Selvagem apresenta muitas de suas dinâmicas sobre projetar o espaço público se abstendo de padrões, criando um espaço interativo importante diante das necessidades dos hábitos de vida contemporâneos.

\section{Projetando espaços públicos}

Projetar equipamentos de urbanidade é uma atividade que envolve um trabalho projetual de intensa análise, visando a alcançar todo um conjunto de barreiras que estão presentes não simplesmente para serem removidas, mas analisadas, revistas, reestruturadas e reinventadas, pois projetar espaços públicos é algo que está além de meramente cumprir metas. Para projetar adequadamente, é preciso cumprir com o dever enquanto arquiteto e urbanista, é se colocar no espaço a ser trabalho enquanto cidadão.

Nesse sentido, para projetar espaços públicos diante de uma abordagem metodológica competente, é preciso realizar a interlocução entre o espaço e a 
sociedade, favorecendo o reconhecimento da importância deste tipo de projeto diante às novas dinâmicas sociais.

\begin{abstract}
Um bom projeto acarretará no melhor aproveitamento dos recursos disponíveis para a sua execução e possibilitará a melhor relação de urbanidade entre os diferentes usos na cidade, proporcionando o usufruto pleno das instalações pelos usuários, que terão o privilégio de ocupar um espaço que lhes ofereça conforto, segurança, acessibilidade e prazer (GATTI, 2013, p. 29).
\end{abstract}

Para a compreensão de como o anteprojeto da praça desenvolvido no presente estudo foi realizado, seguem-se as etapas que conduzem e orientam a compreensão do recorte de implantação conforme as necessidades identificadas, a partir do gerenciamento dos mapas.

Dando andamento na explanação dos resultados da análise na área de estudo, o capítulo 2 do manual (GATTI, 2013) descreve algumas etapas que oferecem suporte para a elaboração de projetos, dentre as quais é aplicada a etapa do Mapeamento do Entorno, através da qual foi possível obter informações sobre as demarcações possíveis para a implantação das áreas verdes, tendo em mente os intempéries positivos e negativos, que podem interferir no desenvolvimento do projeto.

Além disso, realizou-se a demarcação no mapa dos pontos focais que dão visão para a via de acesso, para o campo de futebol e outras potencialidades possíveis. Outro aspecto importante demarcado no mapa, diz respeito aos lugares de interesse, que são espaços significativos do entorno da área que receberá o projeto, sendo estes os núcleos educacionais presentes no perímetro, como também o campo de futebol. A partir dessas informações, buscou-se elaborar um anteprojeto dinâmico, capaz de atender às necessidades dos possíveis usuários.

$\mathrm{Na}$ etapa seguinte, foi elaborado o Mapeamento do Terreno (APÊNDICE D) que, conforme destaca Gatti e Zandonade (2017), a análise das características existentes define as necessidades para a execução técnica do projeto, ao passo que 
também direciona o desenvolvimento projetual, o qual se baseia na realidade identificada e não em ideias preconcebidas.

Partindo dessa análise sobre a realidade da temática em questão, é possível observar que a área estudada apresenta o uso e apropriação do espaço público frente ao entorno do campo de futebol, tornando-se assim um ponto importante, pois estabelece um local de permanecia efêmera, já que o mesmo não existe no presente recorte e ocorre em relação às estruturas existentes, sendo estes, usuários em potencial para a continuidade do projeto.

Com base na análise dos mapas elaborados, pode-se compreender as demandas necessárias para a desenvoltura do projeto, uma vez que com os resultados concluídos a definição do programa se desenvolve continuamente dentro do contexto, no intuito de atender distintos usuários com diferentes atividades de forma dinâmica, que proporcione segurança, acessibilidade e momentos de convívio.

Nesse sentido, Gatti (2017) acrescenta que a definição do programa significa um verdadeiro exercício de pensamento sobre o que este espaço público precisa ter para atender às demandas existentes e, a partir das possibilidades, o projeto deve ser desenvolvido, tomando por embasamento as diversas potencialidades que 0 espaço pode oferecer.

Dessa forma, as demandas de distintos usuários, assim como a carência de áreas verdes, aspectos como a falta de infraestrutura e de equipamentos que incentivem de permanência e o convívio da sociedade com o meio urbano, entre outras características relevantes a serem consideradas, proporcionaram a definição do anteprojeto da praça, como meio de ativação da urbanidade no perímetro definido.

O projeto da praça se apresenta definido em três zonas: a esportiva, que abriga uma quadra de vôlei; um parquinho infantil com designer de labirinto produzidos com pré-moldados de concreto, áreas de convívio pontuais com a utilização de bancos, e uma área de vivência em desnível, que proporciona sombra.

A segunda zona é a de apoio, que abriga os conjuntos de quiosques de prémoldados que repintem sua forma, onde as mesmas também abrigam os banheiros 
e posto policial. Nesse aspecto, a repetição da forma dos módulos para distintos usos proporciona harmonia ao projeto.

A terceira zona abriga as atividades culturais, com área preparada para apresentações através da inserção de um palco que tem por intuito servir de apoio para ações culturais e de interesse da população, como uma área de participação e incentivo ao convívio, proporcionando um enriquecimento das dinâmicas em grupo, a área também abriga os módulos de quiosques.

Os equipamentos então divididos de acordo com a necessidade de cada área. $\mathrm{Na}$ zona esportiva, foi implantada uma quadra de voleibol de dimensões de 18 metros de comprimento por 9 metros de largura.

A área também abriga o playground, que foi desenvolvido com pré- moldados de concreto de dimensões que variam entre 1,0 a 1,20 de altura por 1,0 metro de comprimento, sendo que alguns destes elementos são vazados, de modo que a distribuição dos mesmos forma um labirinto, utilizou-se ainda da inserção de balanços, que foram desenvolvidos sobre módulos de concreto pré-moldado.

Em relação à zona definida como apoio, a área abriga uma sequência de módulos que foram desenvolvidos para servirem de quiosques, como também receberem funções de banheiro e posto policial, sendo que os mesmos são dispostos de maneira que entre a interseção há um espaço entre um módulo e outro.

Já na zona cultural, foi inserido um anfiteatro em desnível a céu aberto, proporcionando maior integração com o meio, com características estruturais que favorecem a acessibilidade. $\mathrm{Na}$ área posterior do anfiteatro, também foi inserida uma área dedicada à arte, com sugestão da pintura da xilogravura.

As edificações que abrangem o perímetro, como os módulos que abrigam quiosques, banheiro e posto policial, se caracterizam por funções importantes dentro do projeto da praça, sendo que a interseção entre módulos chamados neste projeto de caramanchão, também são de apoio, proporcionando a permanecia de usuários ou a exposição temporária, ao passo que o anfiteatro ao ar livre oferece apoio às dinâmicas culturais, como apresentações que possam ser realizadas.

A setorização é a etapa responsável por uma espécie de demarcação do projeto, onde cada atividade será realizada. Esta etapa visa a evitar erros básicos e, segundo Gatti (2017), abrange as seguintes atividades: 
Áreas de piso A dinâmica do piso segue uma paginação de linhas diagonais que produzem a marcação singular proposta no anteprojeto, como também as especificações dos materiais de distintas cores, com marcas de forma diagonal por todo o projeto.

Lazer contemplativo: estar e convívio Estas áreas, como cita Gatti (2017), são destinadas à permanência, com conforto e segurança. Estas áreas são espaços mais reservados, de modo que foram introduzidos no projeto com a criação de jardins que se espalham ao longo de todo o perímetro da praça, variando em suas formas e vegetação.

Lazer ativo: atividades recreativas e esportivas $O$ espaço é responsável por delimitar as atividades que geram grande movimentação, sendo que no presente anteprojeto da praça, definem-se estas atividades na zona esportiva, que abriga um parquinho, espaço este que não é dividido por barreiras ou grades, mas se coloca disponível à utilização de vegetação, como também pelo piso.

Circulação A proposta do anteprojeto é criar de modo geral, um espaço de livre circulação, onde os usuários não serão induzidos a seguir direções guiadas, mas sim, que possam utilizar todo o conjunto de forma livre, sem interferências.

Acessos $A$ ideia do anteprojeto é definir uma área de acessos livres e acessíveis dentro do que condiz com a normatização, como também, estabelecendo dinâmicas coerentes com o recorte de implantação e, ainda, estabelecendo a introdução das dinâmicas de acessibilidade, para que o acesso não se torne restrito ou dificultado de alguma forma.

Estacionamento Pela extensão do projeto e de suas atividades, se fez necessária a inserção de uma área destinada ao estacionamento para carros, motos e bicicletas, tornando o espaço condizente com as necessidades e conceitos de diversidade dos vários tipos de usuários que podem usufruir da praça. $O$ bicicletário foi introduzido na sequência dos demais estacionamentos como forma de incentivar seu uso.

Delimitação de canteiros As áreas que receberam a vegetação em sua maioria seguiram o nível do piso, onde esses canteiros se destacaram no projeto por meio de sua marcação no piso, mas seguindo o nível, como também a criação de canteiro em desnível com a finalidade de marcar áreas no projeto com ponto de 
convívio que seguem uma dinâmica não convencional, conforme o detalhe na figura 19. A proposta projetual se destaca em relação à vegetação, no intuito de criar ao longo de todo o perímetro, canteiros com diferentes tipos de vegetação que produzem sombras, que marquem o ambiente por cores e volumes das copas.

Plano de massas: gramados, forrações, arbustos e arborização Nessa etapa, são realizadas atividades que antecedem a escolha de espécies vegetais para a composição do projeto paisagístico, no intuito de complementar a setorização de ações a serem desenvolvidas no projeto.

O plano de massas consiste na etapa que define as áreas reservadas para gramados, ou que receberão forrações, áreas de arbustos, entre outras que vão compor a paisagem ou criar elementos naturais de contenção. Também nessa etapa são criadas áreas que recebem arborização, que podem estar sobrepostas a outros tipos de vegetação.

A proposta sobre o panorama da vegetação segue com a seleção de espécies nativas e de fácil manejo, sendo que a distribuição ocorre de forma pontual ao longo da praça, marcando o espaço, a singularidade da proposta e a utilização apenas de vegetação arbórea para a criação de uma espaço de convívio e permanência, que se distribui ao longo do projeto.

$\mathrm{Na}$ elaboração do plano de massas, já é possível apresentar um desenho de composição da vegetação, com orientação funcional ou estética, conforme os objetivos de utilização da área.

\section{CONSIDERAÇÕES FINAIS}

O estudo foi desenvolvido no intuito de desvelar as formas de utilização dos espaços públicos em desuso, através da proposta de um anteprojeto de uma praça para a cidade de Santa Helena - PB. Por meio da análise do espaço sob diversas perspectivas e da descrição minuciosa das várias etapas necessárias à elaboração do anteprojeto, entende-se que o objetivo do estudo foi alcançado. 
A princípio, foi constatada a viabilidade de intervenção no espaço em desuso, por estar localizado em área com importantes equipamentos de uso para toda a comunidade. A proposta da praça traz o potencial de incentivar diversas modalidades de equipamentos e formas de uso, abrangendo o âmbito econômico e social, através do lazer, participação e interação, proporcionando resultados positivos para a população local.

Os resultados consistem de uma proposta do anteprojeto da praça, contextualizando as diversas etapas descritas no manual "Espaços Públicos: diagnóstico e metodologia de projeto", com ênfase na análise de viabilidade no uso de espaços que podem ser transformados em instrumentos de lazer, interação e participação da comunidade. A praça foi projetada com base na conceituação teórica e características específicas do local, investigação sobre os fatores que influenciam o uso da área e o potencial de atender às necessidades das pessoas.

Entre as aplicações práticas da praça ora projetada, entende-se que é possível explorar uma variedade de atividades que contribuem para a valorização da cultura regional, o fomento à geração de renda, o desenvolvimento de vínculos com a comunidade local que se apropria do espaço, entre outras possibilidades.

É possível concluir que a criação de ambientes capazes de oferecer significado e conforto à comunidade é essencial para atender às demandas sociais na ocupação de espaços urbanos em desuso e, nesse contexto, o anteprojeto proposto para a criação da Praça da Prosa contribui para a satisfação e o sentimento de pertencimento ao lugar, mostrando a importância de qualificar o espaço público para promover a aceitação dos equipamentos pelas pessoas e, não apenas, tratar a ocupação dessas áreas de maneira secundária e imediatista.

O presente estudo traz a intenção de incentivar a realização de projetos semelhantes para a utilização de espaços públicos de maneira sustentável e coerente com as demandas da comunidade, no sentido de democratizar o acesso aos equipamentos urbanos e proporcionar um ambiente interativo, de acordo com a realidade local. Dessa forma, esse trabalho visa a contribuir para enriquecer o conhecimento acadêmico relativo ao tema e pode ser útil como embasamento para estudos mais aprofundados. 


\section{REFERÊNCIAS BIBLIOGRÁFICAS}

ARCHDAILY. Projetos: praça. 2019. Disponível em: www.archdaily.com.br/ Acesso em: 20 mai. 2019.

ALEX, Sun. Projeto da praça: convívio e Exclusão no Espaço Público. - $2^{\mathrm{a}}$ ed. - São Paulo: Senac, 2011.

BANDEIRA, A. C. Dispositivos de vida pública: revisitando teorias e procedimentos de avaliação dos espaços públicos. Dissertação (Mestrado em Projeto e Cidade) - Universidade Federal de Goiás, Goiânia, 2017.

BORTOLO, C. A. A dinâmica dos espaços públicos de lazer em cidades da aglomeração urbana de Londrina - PR. Tese (Doutorado em Geografia) - Universidade Estadual de Maringá, Maringá - PR, 2015.

CABRAL, T. N. D.; ROSSETTO, A. M.; SABOYA, R. T. Espaço público e urbanidade: estudo da influência de aspectos morfológicos locais sobre a utilização de praças em Florianópolis. Políticas Públicas \& Cidades, v. 4, n. 2, dez., 2016.

COELHO, H. E. A. Cidades para pessoas: urbanismo tático como instrumento de moderação de tráfego para a requalificação de ruas. Dissertação (Mestrado em Geotecnia e Transportes) Universidade Federal de Minas Gerais, Belo Horizonte, 2017.

FRANÇA, J. P. Espaços públicos de lazer e cidade: desdobramentos em Belém- PA, o caso orla portal da Amazônia. Tese (Doutorado em Arquitetura e Urbanismo) - Instituto de Arquitetura e Urbanismo da Universidade de São Paulo, São Carlos, 2018.

FREITAS, D. M. Desvelando o campo de poder dos grandes projetos urbanos da região metropolitana de Belo Horizonte. Tese (Doutorado em Arquitetura e Urbanismo) - Escola de Arquitetura da Universidade Federal de Minas Gerais, Belo Horizonte, 2016.

FREYRE, M. T. S. Intervenção urbana nas orlas do Rio Paraíba do Sul em Campos dos Goytacazes, RJ. Trabalho de Conclusão de Curso (Bacharelado em Arquitetura e Urbanismo) Instituto Federal de Educação, Ciência e Tecnologia Fluminense, Campos dos Goytacazes, 2015.

GATTI, S. Espaços Públicos: diagnóstico e metodologia de projeto. Coordenação do Programa Soluções para Cidades - São Paulo: ABCP, 2013.

GATTI, S; ZANDONADE, P. ESPAÇOS PÚBLICOS. Leitura Urbana e Metodologia de Projeto [dos pequenos territórios às cidades médias]. São Paulo: ABCP, 2017.

GEHL, J. Cidades para pessoas. - 2ª ed. - São Paulo: Perspectiva, 2013. GIL, A. C. Como elaborar projetos de pesquisa. 5 ed. São Paulo: Atlas, 2010.

IBGE. Instituto Brasileiro de Geografia e Estatística. Cidades. 2018. Disponível em: https://cidades.ibge.gov.br/brasil/pb/triunfo/panorama Acesso em: 13 out. 2018.

JACOB, M.; PAGEL, E. C. A praça como instrumento de educação ambiental: uma proposta para Santa Maria de Jetibá - ES. Anais... XVI Encontro Nacional de Tecnologia do Ambiente Construído, São Paulo, set., 2016. Anais... Porto Alegre, ANTAC, 2016. 
LIBÂNIO, A. F. Proposta de mobiliário urbano para a praça Nauro Machado no centro histórico de São Luís: um estudo de conceitos e formas. Trabalho de Conclusão de Curso (Bacharelado em Desenho Industrial) - Universidade Federal do Maranhão, São Luís, 2014.

LIMA, T. C. S.; MIOTO, R. C. T. Procedimentos metodológicos na construção do conhecimento científico: a pesquisa bibliográfica. Revista Katál., Florianópolis, v. 10, n. esp., p. 37-45, 2007.

LYNCH, K. A imagem da cidade. - tradução de maria Cristina Tavares Afonso - Lisboa: Edições 70, 1960.

MARCONI, M. de A; LAKATOS, E. M. Metodologia científica. 5 ed. São Paulo: Atlas, 2007.

MONTEIRO, J. A. C. Proposta metodológica para análise da qualidade urbanística de frentes de água o caso do Porto. Trabalho de Conclusão de Curso (Arquitetura e Urbanismo) - Faculdade de Ciência e Tecnologia, Porto, 2015.

NASCIMENTO, E. P. DO. Trajetória da sustentabilidade: do ambiental ao social, do social ao econômico. Estudos Avançados. São Paulo, v.26, n. 74, p. 51-64, 2012.

NOGUEIRA, P. S. Práticas de arquitetura para demandas populares: a experiência dos arquitetos da família. Dissertação (Mestrado em arquitetura) - Universidade Federal de Minas Gerais, Belo Horizonte, 2010.

PERIM, E. R. A. Uma proposta de intervenção na comunidade "à margem da linha". Trabalho de Conclusão de Curso (Bacharelado em Arquitetura e Urbanismo) - Instituto Federal de Educação, Ciência e Tecnologia Fluminense, Campos dos Goytacazes, 2015.

RODRIGUES, R. F.; LADWIG, N. I. O espaço público na contemporaneidade da cidade: estudo de caso bairro Santa Luzia - Criciúma (SC). Revista Tecnologia e Ambiente, Criciúma (SC), v. 20, 2014.

VELLOSO, B. A. Do bairro à cidade: plano e projeto urbanístico para o Jardim Kantian, Itapeva-SP. Trabalho de Conclusão de Curso (Bacharelado em Arquitetura e Urbanismo) Universidade Estadual Paulista, Presidente Prudente (SP), 2015. 